\title{
THE
}

\section{Cardiac asystole at birth: Is hypovolemic shock the cause?}

Judith S. Mercer

University of Rhode Island, jsmercer@uri.edu

Debra A. Erickson-Owens

University of Rhode Island, dericksonowens@uri.edu

R. Skovgaard

Follow this and additional works at: https://digitalcommons.uri.edu/nursing_facpubs

Terms of Use

All rights reserved under copyright.

\section{Citation/Publisher Attribution}

Mercer, J., Erickson-Owens, D., \& Skovgaard, R. (2009). Cardiac asystole at birth: Is hypovolemic shock the cause? Medical Hypotheses, 72, 458-463. https://doi.org/10.1016/j.mehy.2008.11.019

Available at: https://doi.org/10.1016/j.mehy.2008.11.019

This Article is brought to you for free and open access by the College of Nursing at DigitalCommons@URI. It has been accepted for inclusion in College of Nursing Faculty Publications by an authorized administrator of DigitalCommons@URI. For more information, please contact digitalcommons-group@uri.edu. 


\title{
Cardiac asystole at birth: Is hypovolemic shock the cause? ${ }^{\text {is }}$
}

\author{
J. Mercer ${ }^{\mathrm{a}, \mathrm{b}, *}$, D. Erickson-Owens ${ }^{\mathrm{a}, \mathrm{b}}$, R. Skovgaard ${ }^{\mathrm{c}}$ \\ ${ }^{\text {a }}$ College of Nursing, University of Rhode Island, 2 Heathman Road, Kingston, RI 02881, United States \\ ${ }^{\mathrm{b}}$ Adjunct, Brown University, United States \\ ${ }^{\mathrm{c}}$ Department of Obstetrics and Gynecology, University of Rochester at Highland Hospital, United States
}

\section{A R T I C L E I N F O}

\section{Article history:}

Received 2 September 2008

Accepted 24 November 2008

\begin{abstract}
S U M M A R Y
A birth involving shoulder dystocia can rapidly deteriorate-from a fetus with a reassuring tracing in the minutes before birth, to a neonate needing aggressive resuscitation. Infants experiencing a traumatic birth involving shoulder dystocia may be severely compromised, even when the preceding labor was uncomplicated. This paper presents two cases in which infants had normal heart beats recorded 5$10 \mathrm{~min}$ before birth and were born with cardiac asystole following shoulder dystocia. Often, in cases of shoulder dystocia, infants shift blood to the placenta due to the tight compressive squeeze of the body in the birth canal (along with cord compression) and thereby may be born hypovolemic. Our hypothesis is that the occurrence of sudden cardiac asystole at birth is due to extreme hypovolemic shock secondary to the loss of blood. At birth, the sudden release of pressure on the infant's body results in hypoperfusion resulting in low central circulation and blood pressure. Severe hypovolemic shock from these effects leads to sudden cardiac arrest. Immediate cord clamping maintains the hypovolemic state by preventing the physiologic and readily available placental blood from returning to the infant. Loss of this blood initiates an inflammatory response leading to seizures, hypoxic-ischemic encephalopathy, and brain damage or death. Animal studies have shown that human umbilical stem cells injected into a rat's abdomen after induced brain damage, can protect the rat's brain from developing permanent injury. To prevent damage to newborns, the infant must receive the blood volume and stem cells lost at the time of descent and immediate cord clamping. Recommended countermeasures for research include: (1) resuscitation at the perineum with intact cord; or (2) milking the cord before clamping; or (3) autologous transfusion of placenta blood after the birth; or (4) rapid transfusion of $\mathrm{O}$ negative blood after birth and before seizures begin.
\end{abstract}

(c) 2008 Elsevier Ltd. All rights reserved.

\section{Introduction}

Infants experiencing a traumatic birth involving shoulder dystocia are often severely compromised, even when labor was uncomplicated. The infant emerges hypotonic, with pale white skin color, and no respiratory effort. The heart rate may be depressed or absent. Infants presenting this way are at risk of developing seizures, hypoxic-ischemic encephalopathy (HIE), neurodevelopmental impairment, cerebral palsy (CP), and death. Unfortunately, these situations often result in medico-legal cases. It becomes clear that conscientious care, adhering to current practice recommendations, does not protect against a bad outcome.

Fetal injury following shoulder dystocia is often more severe than warranted by the obvious circumstances. In a review of 56 in-

\footnotetext{
This work has been support by two Grants NIH K23-NR00078 and NIH RO11NR01005-01A2.

* Corresponding author. Present address: 76 Woodbury Road, Cranston, RI 02905, United States. Tel./fax: +4017806750.

E-mail address: jmercer@uri.edu (J. Mercer).
}

fants born in the United Kingdom, Hope and colleagues (1998) point out that many infants experiencing shoulder dystocia died after less than a 5 min delay in delivery-less time than is needed for damage from asphyxia alone. In their review of infants with fatal shoulder dystocia over a two year period, a total of 38 infants (68\%) had no sign of life at birth and fifteen (27\%) were briefly resuscitated and later died [1]. Twenty-five autopsies were performed and $96 \%$ of them revealed signs of acute hypoxic organ damage. The authors cite animal studies that suggest fetuses in good condition should be able to withstand 5-10 min of total anoxia and still respond well to resuscitation.

In many instances shoulder dystocia is not predictable $[1,2]$. Risk identification strategies fail to identify a large portion of cases. Selected delivery by prophylactic cesarean section will not prevent injury to all newborns $[3,4]$.

These observations suggest that factors other than a short episode of hypoxia are involved. The lack of resilience of the infants in these difficult births may be explained by hypovolemic shock due to significant compression of the body and the cord during descent prior to birth. Compromised blood volume, followed by 
sudden release of birth canal pressures, can result in sudden cardiac arrest at birth. The authors use two cases involving shoulder dystocia and cardiac asystole to frame the discussion. Evidence to support this theory is reviewed and recommendations are provided for future research and immediate neonatal management in different settings.

\section{The cases}

The authors had access to birth records for these two cases as either an expert witness or from information shared by a defendant. Table 1 compares details of the two cases and highlights several points for discussion of the potential effect of shoulder dystocia on the neonate.

Case 1: severe shoulder dystocia, seizures, and death

A 35 year old G2 P1 with spontaneous rupture of membranes at $37^{5 / 7}$ weeks was induced. The fetus appeared large upon admission. Her first birth was a vaginal delivery of a $3629 \mathrm{~g}$ male at term.

\section{Labor}

The first stage of labor was $6 \mathrm{~h}$ followed by a $2 \mathrm{~h}$ second stage. Pushing was compromised by a dense epidural. Vacuum assistance was used to gently pull the head through four contractions (the fetus had profuse hair and the cup placement did not achieve optimum suction). The external fetal monitor tracing throughout labor was essentially normal with the baseline rate $150-160 \mathrm{bpm}$ and good accelerations. In the last hour, the baseline rate increased to $165-175 \mathrm{bpm}$.

\section{Delivery}

As the head began to deliver slowly, the fetus was observed by the physician, the mother, and the nurse to be making vigorous efforts to move its head. Over the next $30 \mathrm{~s}$, the head was fully delivered. External fetal monitoring gear was removed with the last observed heart rate of 146-162 bpm immediately after the delivery of the head. The usual shoulder dystocia maneuvers were initiated. With significant effort the baby was successfully rotated using Wood's screw maneuver and the posterior arm was delivered. Traction was required by two providers to deliver the chest and abdomen. The birth of the body occurred 6 min after the monitor was unhooked from the monitor. The cord was clamped and cut immediately and the pale, limp baby was passed to the resuscitation team.

\section{Resuscitation}

The baby weighed $4876 \mathrm{~g}$ and was born with Apgar scores of $0^{1}$, $0^{5}, 0^{10}$. Efforts to resuscitate the infant included a full cardio-pul-

\section{Table 1}

Commonalities between two cases of hypoxic ischemic encephalopathy.

\begin{tabular}{lll}
\hline & Case 1 & Case 2 \\
\hline Length of labor & & \\
1st stage & 6 & 1 \\
2nd stage & 2 & $160-180 \mathrm{bpm}$ \\
Last record heart rate (range) & $146-162 \mathrm{bpm}$ & $9 \mathrm{lbs} 4 \mathrm{oz}$ \\
Infant's birth weight & $10 \mathrm{lbs} 12 \mathrm{oz}$ & $5-10 \mathrm{~min}$ \\
Time from birth of head to & $6 \mathrm{~min}$ & \\
$\quad$ & & \\
$\quad$ delivery of body & Immediate & Before delivery of shoulders \\
Cord clamping & 6.9 @ $30 \mathrm{~min}$ & 7.11 (cord) 6.72 @ 60 min \\
Cord or first pH & $23 \mathrm{~min}$ & $18 \mathrm{~min}$ \\
Length of asystole & $1 \mathrm{~h}$ & $1.5 \mathrm{~h}$ \\
First seizure & Severe & Severe \\
Hypotension & $47 \%$ @ h & $38 \%$ at $1 \mathrm{~h}$ \\
Hematocrit after birth &
\end{tabular}

monary resuscitation. Endotracheal intubation was performed by the anesthesiologist at $1 \mathrm{~min}$ of age. Endotracheal epinephrine was given on four occasions: at 1, 6, 14 and $18 \mathrm{~min}$. Within $3 \mathrm{~min}$ of the birth, a pediatrician was present. After $15 \mathrm{~min}$, the baby was moved to the nursery and an umbilical venous (UV) catheter was placed. At $16 \mathrm{~min} 50 \mathrm{~mL}$ of normal saline was given with $8 \mathrm{~mL}$ of bicarbonate solution. At $18 \mathrm{~min}$ epinephrine $0.3 \mathrm{mg}$ was given by UV line. An additional $4 \mathrm{~mL}$ of bicarbonate was given at $22 \mathrm{~min}$. At $23 \mathrm{~min}$, a heart rate (HR) was observed. The first arterial blood gas (ABG) was collected from the radial artery at $31 \mathrm{~min}$ of life, showing pH 6.73, pCO2 $112 \mathrm{PO} 2$ of 65 and $\mathrm{O}_{2}$ saturation of $66 \%$. Blood pressure (BP) was $69 / 39$ with a HR of 160 , but at $1.5 \mathrm{~h}$ the BP dropped to 51/21 prompting the initiation of dopamine at $5 \mathrm{mcg} / \mathrm{kg} /$ minute. At $1 \mathrm{~h}$ of age seizure activity was noted and phenobarbital therapy initiated.

\section{NICU Course}

The infant was transferred to the Level III Neonatal Critical Care Unit of a nearby hospital. Admission vital signs on dopamine included HR 121 , BP $55 / 24$, and temperature of $37.5^{\circ} \mathrm{C}$. The baby was intubated and on a ventilator. The first hematocrit and hemoglobin $(\mathrm{H} \& \mathrm{H})$ noted at five hours of age was $43.7 \%$ and $14.7 \mathrm{~g} / \mathrm{dL}$. Vital functions of respiration, renal function, temperature control, and BP stability recovered by three days of age. Dopamine was discontinued. There was profound brain damage.

\section{Outcome}

The infant had severe feeding problems with poor suck and frequent aspiration necessitating a PEG tube. Regurgitation and aspiration of food remained a major problem. At three weeks of age the child had not recovered any significant neurologic function. He was discharged home with hospice support. Death at home at two months of age was secondary to aspiration pneumonia. No placental pathology was noted. An autopsy was not performed.

Case 2: severe shoulder dystocia, seizures and cerebral palsy

A 22 year old G1P0 at 41 $4 / 7$ weeks was induced after a normal prenatal course.

\section{Labor}

First stage was progressive over $11 \mathrm{~h}$. Second stage lasted $1 \mathrm{~h}$. The fetal heart tracing was reactive throughout labor with some tachycardia (160-180 bpm) and marked variability in the last half hour.

\section{Delivery}

The fetal head was slow to emerge. Time from delivery of the head to the delivery of the body was estimated to be between 5$10 \mathrm{~min}$. A nuchal cord was present and was cut about two minutes before delivery.

\section{Resuscitation}

The infant appeared floppy, pale and was unresponsive. Apgar scores were $0^{1}, 0^{5}, 0^{10}$. The infant was bagged and masked and then intubated within three minutes. Pediatrics was in attendance by $15 \mathrm{~min}$. The infant weighed $4214 \mathrm{~g}$. A cord blood gas showed $\mathrm{pH}$ 7.11, $\mathrm{CO}_{2} 67$, base deficit of -9.6 . Two doses of epinephrine were given and a heart rate of 100 was heard after the second dose at 18 min after birth. The infant was taken to the nursery and placed on a ventilator. On admission to the nursery, an $\mathrm{ABG}$ revealed a $\mathrm{pH}$ of 6.9. An umbilical artery catheter was placed and albumin was given twice. The systolic BP fell to $40 \mathrm{mmHg}$ and dopamine was started. Generalized seizure activity (bicycling and lip smacking) was noted between one and two hours. The infant was transferred 
to a Level III Nursery. Initial H\&H was 38\% and13 g/dL. Examination of the placenta revealed no pathology.

\section{Outcome}

The child survived with $\mathrm{CP}$ (can walk but not run) and developmental delay. The child attends school but is three years below grade level. Experts offered that there was clear evidence of acute perinatal damage on MRI [5].

\section{The hypothesis}

Our hypothesis is that the sudden cardiac asystole noted in both of these cases is due to severe hypovolemic shock. The mechanism involved is a compressive squeeze of the body and umbilical cord as the large infant descends through the birth canal. This compression causes some volume of blood to be retained in the placenta rather than returning to the infant. At birth, when the baby's body is freed, there is a sudden release of the pressure especially on the infant's peripheral circulation. With insufficient blood supply to perfuse the entire body and maintain the central circulation, the heart stops beating. The usual practice of immediate cord clamping prevents the placental circulation from restoring the lost volume in a homeostatic fashion. The result is a severely compromised infant, who if resuscitated, may experience hypoxic-ischemic encephalopathy (HIE) as a result of low blood volume, the loss of red blood cells (RBCs) for oxygenation and hematopoietic stem cells essential for healing and repair.

We have been unable to find any current hypotheses to explain the mechanism of sudden cardiac asystole after birth in the medical literature. The resulting damage, hypoxic-ischemic cerebral injury, is believed to be a result of impaired cerebral blood flow occurring as a consequence of "interruption in placenta blood flow and gas exchange" with which we agree [6]. Most focus is given to what happens at the cellular level. Volpe discusses implications of reduced cerebral blood volume but does not link it to the infant's overall general blood volume [7]. The following discussion dissects each part of the hypothesis and provides evidence as available.

\section{The second stage "squeeze"}

Blood volume loss, significant enough to cause hypovolemic shock at birth, may occur as the infant descends into the birth canal prior to shoulder dystocia. The mechanism may be the compressive squeeze of the infant as it traverses the tight birth canal places pressure on the umbilical cord with or without a cord entanglement [8]. The soft-walled umbilical vein is more easily occluded than the arteries $[9,10]$. The muscular-walled, high-pressure arteries continue to move blood from the fetus to the placenta, while return flow from the placenta to the fetus in the thin-walled vein can easily be impeded. Thus there is a net transfer of blood volume from the fetus to the placenta. Few changes other than tachycardia may be seen on the fetal monitor tracing. Yet the stage is set for dramatic compromise at birth when the surrounding pressure is released and the neonate is left severely volume depleted.

\section{Effects of vaginal wall pressure}

Compensating for the loss of blood volume, pressure from the vaginal walls acts as an anti-shock garment to maintain blood pressure, circulation, and HR while the infant is in the vagina. The vaginal wall pressure most likely supports a transfer of blood from the peripheral circulation to the central circulation (brain, heart, lungs, kidneys) allowing the infant to maintain a near normal heart rate [11]. Anti-shock garments have been shown to provide $20-50 \mathrm{mmHg}$ pressure to the lower body [12]. As the infant is born, there is sudden loss of the supporting vaginal wall pressure of the birth canal. This loss of surrounding pressure is akin to suddenly removing an anti-shock garment-it creates an immediate opening of the peripheral circulation and thus reduces the central circulation resulting in a drop of blood pressure (BP). The reduction in central circulation decreases blood flow to the heart causing hypoxia/anoxia and it immediately stops beating [11].

\section{Hypovolemic shock}

Hypovolemic shock due to inadequate circulating blood volume has the potential to cause profound damage quickly and consistently, including asystole. Hypovolemia, hypotension, hypovolemic shock and anemia have been documented in infants born with nuchal cords that were cut before delivery of the shoulders [8,13-15]. $\mathrm{CP}$ has been reported in cases when a nuchal cord is cut and then shoulder dystocia arises even with only a brief delay in the delivery [16-18]. Reports of reduction in birth weight with early clamping support the theory that this intervention can reduce the amount of placental transfusion [19-21] .

\section{Sudden cardiac arrest}

The volume depleted infant is born in a state of hypovolemic shock and does not have enough blood in the central circulation to adequately oxygenate and perfuse the heart [22]. The heart suddenly stops beating secondary to hypoxia, resulting in immediate cardiac arrest [23]. Both of our case infants had normal heart rates recorded less than 6-10 min prior to the arrest. One infant was seen moving his head 6 min before birth yet was born lifeless.

\section{Immediate cord clamping}

Immediate cord clamping (ICC) leaves the infant with only the blood volume that was in his body at the moment of birth. ICC after a normal birth has been shown to result in a $30 \%$ reduction in blood volume and a 50\% deficit of RBCs [24]. Blood loss or the blood diverted to the placenta due to the birth canal squeeze also creates a significant reduction of blood volume at birth.

Infants who undergo immediate cord clamping after a normal birth are left with about $70 \mathrm{~mL} / \mathrm{kg}$ while infants with delayed cord clamping obtain about $90 \mathrm{~mL} / \mathrm{kg}$ [24]. For a $4000 \mathrm{~g}$ infant, this difference is $280 \mathrm{~mL}$ versus $360 \mathrm{~mL}$ for the circulating blood volume [24]. Thus, delayed cord clamping or milking the cord will provide about $80 \mathrm{~mL}$ of blood for circulatory adjustments for an infant of this size. In the first few minutes after birth, the pulmonary capillary bed becomes a huge reservoir that must be rapidly perfused for the first time as the cardiac output to the lung shifts from $8 \%$ in utero to $50 \%$ as breathing is established [25]. This $80 \mathrm{~mL}$ of blood is not extra blood-it has been the respiratory blood in utero [26].

Loss of red blood cells. Yao and colleagues found that infants with a delay in cord clamping of three minutes obtain approximately $50 \%$ more RBCs [24]. RBCs play a critical role in oxygen and carbon dioxide transport. Jones estimated that infants need approximately $45 \mathrm{mg} / \mathrm{kg}$ RBCs for adequate oxygen-carrying capacity [27]. The only infants in the study of Yao and colleagues who obtained $45 \mathrm{mg} / \mathrm{kg}$ RBCs were those infants whose clamping was delayed for three minutes [24]. Whatever amount of blood is trapped in the placenta because of the second stage squeeze would add to RBC loss.

Measurement of blood volume and red cell volume. It is worth noting that accurate measurement of blood volume and red cell volume is notoriously difficult. The hematocrit level, being simple to obtain, is most commonly used. But it can be unreliable in circumstances of trauma or stress. Faxelius et al. measured red cell 
volume by tagging the RBCs with non-radioactive chromium and found that infants with a history of asphyxia often had a low red cell volume even if no signs of blood loss were present [28]. Others studied blood volume in the 1 st hour in asphyxiated infants using $\mathrm{I}^{135}$ tagged albumin and found larger blood volumes in asphyxiated babies [29]. However, Yao points out that the infants she studied had asphyxia livida (plethoric) and that infants with asphyxia pallida (pale) may have less blood volume. Better techniques to assess infant blood volume are needed to answer these questions. Measurement of superior vena cava flow may offer some insight but has only been reported in preterm infants [30].

\section{Inflammation and stem cells}

Two separate animal studies have demonstrated inflammation caused by blood loss alone [31,32]. Meier and colleagues (2006) demonstrated that loss of blood volume alone to the brain results in inflammation. Through ligation of the rat pup's carotid artery, a progressive inflammatory process was created leading to neuronal death in the brain and resulting in spastic paresis. When human UCB cells were injected into the abdomens of affected rat pups within $24 \mathrm{~h}$ of injury, spastic paresis did not develop in the experimental group. Administering the UCB cells to the damaged pups later than $24 \mathrm{~h}$ did not prevent damage. Upon histologic examination of the rat brains at 21 days after the injury, Meier et al. [32] found that the human UCB stem cells crossed the blood-brain barrier, surrounded and infiltrated the damaged areas and appeared to provide scaffolding for repair. These cells were not found in any intact, uninjured areas suggesting that inflammatory factors (cytokines) from the damage areas signaled the stem cells [33]. We estimated that our case infants lost about one billion stem cells because of second stage compression compounded by immediate cord clamping. Might the stem cells have played a role in healing their deficits? [34].

\section{Resuscitation}

Developing evidence highlights perfusion as the key factor in adult resuscitation, such as in cardiac arrest. The 2005 American Heart Association guidelines for CPR places increasing importance on chest compressions over ventilations [35]. Ewy advocates reconceptualizing CPR as "cardiocerebral" resuscitation (CCR) and recommends continuous chest compressions (CCC-CPR), without interruption for ventilations [36]. This recommendation is based on animal models in which cardiac arrest survival increased to $80 \%$ when CCC-CPR was applied, compared to $13 \%$ with standard CPR [37]. Maintenance of perfusion to the heart and brain was the critical factor in protecting function of those organs and impacting survival. Hypovolemic infants, such as our case infants, lack the crucial blood volume needed to adequately perfuse the heart and brain.

\section{Research needed: Preventing hypovolemic shock at birth}

The sight of the pale white, toneless infant at birth invokes fear in all caregivers. These infants are very difficult to resuscitate. The fear of managing them is real and appropriate. Often, a properly conducted resuscitation revives a terminally damaged infant (as in our first case) or does not revive the infant at all. Assisting infants to obtain their adequate blood volume at birth may be their only hope for any recovery. The current management in an American hospital is to cut the cord immediately and take the infant to the warmer for resuscitation. In out-of-hospital birth settings in this country and around the world, the option of resuscitation at the perineum with an intact cord is more common.
The current treatment for infants with cardiac asystole and HIE involve supportive care. This includes intubation, all NICU modalities, phenobarbital for seizures and hypothermia treatment for HIE $[6,38]$.

We offer four options for research that may potentially increase blood volume to newborns and thus prevent hypovolemic shock and its sequelae. Research involving these recommendations will require rethinking of long held beliefs and practices among care providers in birth/delivery/operating rooms. These suggestions can be incorporated with neonatal resuscitation guidelines, which to date have not addressed the potential value of delayed cord clamping [39]. We suggest that these options may be effective at preventing harm to newborns as well as treating the damage from HIE. Cases involving resuscitation with these methods are presented elsewhere [40].

The recommendations are as follows (1) resuscitate the infant at the perineum without clamping the cord, (2) milk the cord at birth of an extremely depressed infant before cutting it, (3) provide the infant with a transfusion of its own blood by withdrawing it from the placental end of the clamped umbilical cord and finally, (4) build blood volume after birth by transfusing with $O$ negative blood if the prior options are not possible or do not work. Issues involved in each method are presented below.

\section{Resuscitation at the perineum}

Keeping a depressed infant at the perineum seems counterintuitive. However, a full resuscitation can be done at the perineum without cutting the cord. Holding the infant at the perineum for drying, stimulation, and resuscitation offers the opportunity for some of the blood volume to return to the infant. This method allows the infant to get his own hemoglobin F, stem cells and the appropriate cytokine cocktail to guide the stem cells. The placental system continues to circulate in the first few minutes of life until the cord stops pulsating [41,42]. Unless the mother is bleeding profusely, there is no reason to suspect separation of the placenta.

\section{Milking the cord}

This option involves lowering the infant as much as possible and vigorously milking the cord two to four times before cutting it and taking the infant to the warmer [43,44]. Milking the umbilical cord may offer a viable option to prevent hypovolemic shock at birth when time and speed are critical factors. A review of the literature on umbilical cord milking or stripping supports this technique as a safe intervention resulting in higher neonatal hemoglobin levels and red cell volume at birth.

In nine controlled trials involving 803 babies (1949-2008), 350 infants had immediate cord clamping, 116 infants had delayed cord clamping, and 337 infants had umbilical cord milking [4351]. Infants with immediate cord clamping had significantly lowered $\mathrm{H} \& \mathrm{H}$ levels than infants with delayed cord clamping or cord milking. No increase in jaundice or symptomatic polycythemia was reported among the infants in the studies.

\section{Autologous transfusion of cord blood}

The third intervention involves collecting cord blood under sterile conditions, using $60 \mathrm{cc}$ syringes with appropriate additive, from the maternal side of the clamped umbilical cord. The blood can then immediately be transferred to the infant, at a volume of $15-20 \mathrm{~mL} / \mathrm{kg}$. The safety and efficacy of this intervention has been documented [52,53]. We believe that it will be imperative that the blood volume lost should be returned to the infant before one hour of age or about the time that seizures may begin (in our two cases seizures began at 60-90 min-see Table 1 ). 


\section{Transfusion of fresh whole blood}

Given strong evidence that severe volume depletion can cause hypoxia resulting in serious and irreversible injury to newborns, a transfusion as soon as possible with fresh whole $O$ negative blood at $10-20 \mathrm{~mL} / \mathrm{kg}$ may be indicated when the previous measures are impossible or ineffective. Though this is the least optimal method, it may have helped our case infants and others like them as they had low hematocrit levels for term infants and needed vasopressors to maintain blood pressure. It does not provide the infant with hemoglobin F or activated stem cells, but it does supply red blood cells with oxygen carrying capacity and volume.

\section{Caveat: cord blood gases}

There is no immediate benefit to the infant for cutting the cord early in order to obtain blood gases. The infant is resuscitated by clinical appearance and responses while a result of any cord gases obtained is pending. We acknowledge that there may be some clinical advantage later in care but the irreversible damage may have occurred [54]. The act of cutting the cord to obtain the gases prevents any opportunity to correct the infant's acid-base balance by extra-uterine resuscitation with intact cord. In addition, it limits transfusion of blood in cases where the infant is volume depleted, setting up a likelihood of additional hypoxic-ischemic injury of major organs. Further study may reveal that, when indicated, obtaining venous and arterial samples from an intact cord may prove safe and useful. Our case infants may have had different outcomes with resuscitation using their own blood.

\section{Summary}

In cases of shoulder dystocia, infants shift blood to the placenta due to the tight squeeze of the birth canal and thereby are born hypovolemic. At birth, the sudden release of pressure results in hypoperfusion and low blood pressure. Severe hypovolemic shock from these effects can result in sudden cardiac arrest. Immediate cord clamping maintains the hypovolemic state and delays treatment until volume expanders can be given artificially through an umbilical catheter instead of using physiologic and readily available placental blood. Blood loss sets off an inflammatory cascade which can result in seizures, HIE and later brain damage. To prevent these conditions, the infant must obtain the blood volume lost with the squeeze. Recommended countermeasures for research are: (1) resuscitation at the perineum with intact cord; or (2) milking the cord before clamping; or (3) autologous transfusion of placenta blood after the birth; or (4) rapid transfusion of $O$ negative blood.

\section{Acknowledgment}

We are grateful to Dr. Peter Reagan who sent us a case description and raised the importance of publishing the case to open discussion of these vital issues. We dedicate this chapter to all the infants, like Nicholas, who lost their lives to teach us.

\section{References}

[1] Hope P et al. Fatal shoulder dystocia: a review of 56 cases reported to the confidential enquiry into stillbirths and deaths in infancy. Br J Obstet Gynaecol 1998;105(12):1256-61.

[2] Jevitt CM. Shoulder dystocia: etiology, common risk factors, and management. J Midwifery Womens Health 2005;50(6):485-97.

[3] Dildy GA, Clark SL. Shoulder dystocia: risk identification. Clin Obstet Gynecol 2000;43(2):265-82.

[4] Sokol RJ, Blackwell SC, ACOG. ACOG practice bulletin: shoulder dystocia. Int J Gynaecol Obstet 2003;80(1):87-92.
[5] Barkovich AJ. Pediatric neuroimaging, vol. 1. New York: Raven Press; 1990. p. 355.

[6] Perlman JM. Intervention strategies for neonatal hypoxic-ischemic cerebral injury. Clin Thera 2006;28(9):1353-65.

[7] Volpe JJ. Neurology of the newborn. 4th ed. Philadelphia: Saunders; 2001. p. 912.

[8] Mercer JS et al. Nuchal cord management and nurse-midwifery practice. J Midwifery Womens Health 2005;50(5):373-9.

[9] Ball RH, Parer JT. The physiologic mechanisms of variable decelerations. Am J Obstet Gynecol 1992;166(6 Pt 1):1683-8 [discussion 1688-9].

[10] Dhar KK, Ray SN, Dhall GI. Significance of nuchal cord. J Indian Med Assoc 1995;93(12):451-3.

[11] Miller S et al. The pilot study of the non-pneumatic anti-shock garment (NASG) in women with severe obstetric hemorrhage: combined results from Egypt and Nigeria. Int J Gynaecol Obstet 2006;94(Suppl. 2):S154-6.

[12] Hensleigh P. Anti-shock garment provides resuscitation and haemostasis for obstetric haemorrhage. BJOG 2002;109:1377-84.

[13] Vanhaesebrouck P et al. Tight nuchal cord and neonatal hypovolaemic shock Arch Dis Child 1987;62(12):1276-7.

[14] Cashore WJ, Usher R. Hypovolemia resulting from a tight nuchal cord at birth Pediatr Res 1973;7:399.

[15] Shepherd AJ, Richardson CJ, Brown JP. Nuchal cord as a cause of neonatal anemia. Am J Dis Child 1985;139:71-3.

[16] Iffy L, Varadi V. Cerebral palsy following cutting of the nuchal cord before delivery. Med Law 1994;13:323-30.

[17] Iffy L, Varadi V, Papp E. Untoward neonatal sequelae deriving from cutting of the umbilical cord before delivery. Med Law 2001;20(4):627-34.

[18] Nelson KB, Grether JK. Potentially asphyxiating conditions and spastic cerebral palsy in infants of normal birth weight. Am J Obstet Gynecol 1998;179(2): 507-13.

[19] Osak R et al. Nuchal cord evident at birth impacts on fetal size relative to that of the placenta. Early Human Develop 1997;49(3):193-202.

[20] Prendiville WJ et al. The Bristol third stage trial: active versus physiological management of third stage of labour. BMJ 1988;297(6659):1295-300.

[21] Rogers J et al. Active versus expectant management of third stage of labour: the Hinchingbrooke randomised controlled trial. Lancet 1998;351(9104): 693-9.

[22] Copstead L, Banasik JL. Pathophysiology: biological and behavior perspectives 2nd ed. Philadephia: W.B. Saunders Company; 2000.

[23] Guyton AC, Hall JE. Textbook of medical physiology, 11th ed., vol. 1. Philadelphia: Elsevier Saunders; 2006. p. 1116.

[24] Yao AC, Moinian M, Lind J. Distribution of blood between infant and placenta after birth. Lancet 1969;2(7626):871-3.

[25] Blackburn S. Maternal, fetal and neonatal physiology. 2nd ed. Philadelphia: W.B. Saunders Company; 2003. p. 781

[26] Mercer J, Skovgaard R. Neonatal transitional physiology: a new paradigm. Perinat Neonatal Nurs 2002;15(4):56-75.

[27] Jones JG et al. Total circulating red cells versus haematocrit as the primary descriptor of oxygen transport by the blood. Brit J Haemat 1990;76:288-94.

[28] Faxelius G, Raye J, Gutberlet Rea. Red cell volume measurements and acute blood loss in hight-risk newborn infants. J Pediatr 1977;90:273-81.

[29] Yao AC, Lind J. Placental transfusion. Am J Dis Child 1974;127(1):128-41.

[30] Evans $\mathrm{N}$ et al. Which to measure, systemic or organ blood flow? Middle cerebral artery and superior vena cava flow in very preterm infants. Arch Dis Child Fetal Neonatal Ed 2002;87(3):F181-4.

[31] Rajnik $M$ et al. Induction of early inflammatory gene expression in a murine model of nonresuscitated, fixed-volume hemorrhage. Shock 2002;17(4):322-8

[32] Meier C et al. Spastic paresis after perinatal brain damage in rats is reduced by human cord blood mononuclear cells. Pediatr Res 2006;59(2):244-9.

[33] Imitola J et al. Directed migration of neural stem cells to sites of CNS injury by the stromal cell-dervived factor $1 \alpha /$ CXC chemokine receptor 4 pathway. PNAS 2004;101(52):18117-22.

[34] Iffy L et al. Collection of fetal blood for stem cell research and therapy. Med Law 2006;25(3):553-61.

[35] AHA. American Heart Association guidelines for cardiopulmonary resuscitation and emergency cardiovascular care. Circulation 2005;112(IV): $1-203$.

[36] Ewy GA. Cardiocerebral resuscitation: the new cardiopulmonary resuscitation. Circulation 2005;111(16):2134-42.

[37] Ewy GA et al. Cardiocerebral resuscitation for cardiac arrest. Am J Med 2006;119(1):6-9.

[38] Shankaran S et al. Whole-body hypothermia for neonates with hypoxicischemic encephalopathy. N Engl J Med 2005;353(15):1574-84.

[39] Kattwinkel J, editor. Textbook of neonatal resuscitation. Washington, DC: American Academy of Pediatrics and American Heart Association; 2006.

[40] Mercer J, Skovgaard R. Fetal to neonatal transition: first do no harm. In: Downe S, editor. Norma childbirth: evidence and debate. Edinburgh: Elsevier; 2004.

[41] Stembera ZK, Hodr J, Janda J. Umbilical blood flow in healthy newborn infants during the first minutes after birth. Am J Obstet Gynecol 1965;91:568-74.

[42] Stembera ZK, Hodr J, Janda J. Umbilical blood flow in newborn infants who suffered intrauterine hypoxia. Am J Obstet Gynecol 1968;101(4):546-53.

[43] Hosono $S$ et al. Umbilical cord milking reduces the need for red cell transfusions and improves neonatal adaptation in infants born less than 29 weeks' gestation: a randomized controlled trial. Arch Dis Child Fetal Neonata Ed 2008;93(1):F14-9. 
[44] Colozzi A. Clamping of the umbilical cord: Its effect on the placenta transfusion. NEJM 1954;250(15):629-32.

[45] Siddall R, Crissey R, Knapp W. Effects of cesarean section babies of stripping or milking of the umbilical cord. Am J OB GYN 1952;63(5):1059-64.

[46] Siddall RS, Richardson RP. Milking or stripping the umbilical cord; effect on vaginally delivered babies. Obstet Gynecol 1953;1(2):230-3.

[47] Lanzkowsky P. Effects of early and late clamping of umbilical cord on infant's haemoglobin level. Br Med J 1960;5215:1777-82.

[48] McCausland A, Holmes F, Schumann W. Management of cord and placental blood and its effect upon the newborn: part 1. California medicine 1949;71(3): 190-6.

[49] Usher R, Shephard M, Lind J. The blood volume of the newborn infant and placental transfusion. Acta Paediatr 1963;52:497-512.
[50] Walsh SZ. Early clamping versus stripping of card: comparative study of electrocardiogram in neonatal period. Br Heart J 1969;31(1):122-6.

[51] Whipple GA, Sisson TR, Lund CJ. Delayed ligation of the umbilical cord; its influence on the blood volume of the newborn. Obstet Gynecol 1957;10(6): 603-10.

[52] Strauss RG et al. Circulating RBC volume, measured with biotinylated RBCs, is superior to the Hct to document the hematologic effects of delayed versus immediate umbilical cord clamping in preterm neonates. Transfusion 2003;43(8):1168-72.

[53] Ballin A et al. Autologous umbilical cord blood transfusion. Arch Dis Child Fetal Neonatal Ed 1995;73(3):F181-3.

[54] Nodwell A et al. Placental compared with umbilical cord blood to assess fetal blood gas and acid-base status. Obstet Gynecol 2005;105(1):129-38. 